\title{
BMJ Open Burnout and compassion fatigue among organ and tissue donation coordinators: a scoping review
}

\author{
Vanessa Silva e Silva (10 , ${ }^{1,2}$ Laura Hornby, ${ }^{1,2}$ Joan Almost, ${ }^{3}$ Ken Lotherington, ${ }^{2}$ \\ Amber Appleby, ${ }^{4}$ Amina Regina Silva, ${ }^{1,2}$ Andrea Rochon, ${ }^{1,2}$ Sonny Dhanani ${ }^{5}$
}

To cite: Silva e Silva V, Hornby L, Almost J, et al. Burnout and compassion fatigue among organ and tissue donation coordinators: a scoping review. BMJ Open 2020;10:e040783. doi:10.1136/ bmjopen-2020-040783

- Prepublication history and additional material for this paper is available online. To view these files, please visit the journal online (http://dx.doi.org/10. 1136/bmjopen-2020-040783)

Received 21 May 2020 Revised 27 0ctober 2020 Accepted 06 November 2020

D) Check for updates

C Author(s) (or their employer(s)) 2020. Re-use permitted under CC BY-NC. No commercial re-use. See rights and permissions. Published by BMJ.

${ }^{1}$ Research Institute, Children's Hospital of Eastern Ontario, Ottawa, Ontario, Canada ${ }^{2}$ Organ Donation and Transplantation, Canadian Blood Services, Ottawa, Ontario, Canada

${ }^{3}$ School of Nursing, Queen's University, Kingston, Ontario, Canada

${ }^{4}$ Royal Columbian Hospital, New Westminster, British Columbia, Canada

${ }^{5}$ Critical Care, Children's Hospital of Eastern Ontario, Ottawa, Ontario, Canada

Correspondence to

Dr Laura Hornby;

Ihornby@uottawa.ca

\section{ABSTRACT}

Objectives To collate and synthesise available literature on burnout and compassion fatigue (CF) among organ and tissue donation coordinators (OTDCs) and to respond to the research question: what is known about burnout and $\mathrm{CF}$ among OTDCs worldwide?

Design Scoping review using Joanna Briggs Institute methodology for scoping reviews.

Data sources Medline, EMBASE, PsycINFO, CINAHL, LILACS, PTSpubs and grey literature (ResearchGate, OpenGrey, Organ Donation Organization (ODO) websites, open access theses and dissertations) up to April 2020.

Study selection Studies reporting aspects of burnout and CF among OTDCs, including risk and protective factors.

Data extraction Two reviewers independently screened the studies for eligibility and extracted data from chosen sources using a data extraction tool developed for this study; NVIVO was used to perform a qualitative directed content analysis.

Results The searches yielded 741 potentially relevant records, of which 29 met the inclusion criteria. The majority of articles were from the USA $(n=7,24 \%)$, Canada $(n=6,21 \%)$ and Brazil $(n=6,21 \%)$, published between 2013 and $2020(n=13,45 \%)$ in transplant journals $(n=11$, $38 \%)$ and used a qualitative design approach $(n=12$, $41 \%)$. In the thematic analysis, we classified the articles into five categories: (1) burnout characteristics, (2) CF characteristics, (3) coping strategies, (4) protective factors and (5) ambivalence.

Conclusion We identified aspects of burnout and CF among OTDCs, including defining characteristics, demographic predispositions, protective factors, coping strategies, precursors, consequences and personal ambivalences. Researchers described burnout and CF characteristics but did not use consistent terms when referring to $\mathrm{CF}$ and burnout, which may have hindered the identification of all relevant sources. This gap should be addressed by the application of consistent terminology, systematic approaches and appropriate research methods that combine quantitative and qualitative investigation to examine the underlying reasons for the development of burnout and CF among OTDCs.

\section{INTRODUCTION}

Stressors from the workplace can impact healthcare professionals (HCPs) physically and emotionally, ${ }^{1}$ contributing to the

\section{Strengths and limitations of this study}

This is the first scoping review about burnout and compassion fatigue (CF) among organ and tissue donation coordinators (OTDCs).

- Our search was comprehensive and we included an extensive body of literature, across conditions and study designs.

- Our results may have omitted evidence in languages other than English, Portuguese, French and Spanish, although those are the languages of the countries that have the OTDC role most developed and established.

- Because a scoping review approach was used, the quality of the articles was not assessed prior to inclusion.

- Characteristics of burnout and CF were identified in multiple documents, although there was a lack of consistency in the use of terminology about burnout and CF. We argue that there is a need for more indepth analysis on burnout and CF among OTDCs to guide future interventional studies.

development of workplace-related issues, such as compassion fatigue (CF) and burnout. ${ }^{23} \mathrm{CF}$ is a result of the constant exposure to others' suffering, often called secondary trauma or vicarious trauma. Burnout is a result of prolonged and excessive exposure to interpersonal and emotional stressors in the workplace. ${ }^{2-4}$ Burnout is a complex, multidimensional syndrome characterised by three underlying factors: exhaustion, cynicism (depersonalisation) and inefficacy (reduced personal accomplishment). ${ }^{4}$ Both $\mathrm{CF}$ and burnout can negatively affect HCPs' efficiency and quality of life. ${ }^{1}$

The development of $\mathrm{CF}$ and burnout in HCPs may result in negative consequences for healthcare organisations and patients. ${ }^{5}$ Dealing with burnout and CF may be overwhelming, potentially causing low job performance and indirectly affecting healthcare institutions due to increases in absenteeism and turnover rates. In addition, patients 
can be affected as there is a risk of increased medical errors diminishing patient safety. ${ }^{5}$ Impacts on healthcare systems and patient care may be short term or long term and could have quality, safety and financial implications.

The concepts of burnout and CF have been explored among nurses. A qualitative systematic review summarised the experiences of $\mathrm{CF}$ in direct care nurses and concluded that nurses' constant exposure to psychosocial stressors could lead to $\mathrm{CF}^{6}{ }^{6}$ A systematic review synthesised the literature related to the prevalence of $\mathrm{CF}$ and burnout among HCPs in intensive care units, indicating that a nurse's exposure to emotionally charged environments can result in an increased risk of burnout or $\mathrm{CF}^{7}$ Therefore, nurses are at risk of developing burnout or $\mathrm{CF}$ as they are constantly exposed to human suffering and work stressors.

Although burnout and CF have been studied among nurses, little is known about the prevalence among organ and tissue donation coordinators (OTDCs). OTDCs are usually registered nurses equipped with clinical expertise, interpersonal skills, and critical care experience and background. They receive specific training from the Organ Donation Organization (ODO) to learn how to manage organ donation cases and provide adequate support to hospital staff and families during all steps of the donation process. They play a role in supporting the detection of potential donors, approaching families for consideration of organ donation, maintenance of donors and connecting the hospital with external resources at the ODO. ${ }^{8}$ OTDCs work in a fast-paced environment, facing high-pressure scenarios, and are frequently exposed to job stressors. ${ }^{910}$ Due to the nature of their role, OTDCs are regularly exposed to human suffering, grieving and death, potentially influencing the levels of psychological and psychosocial-related stress. ${ }^{39}$ Coping with all of these stressors and pressure may be overwhelming for OTDCs, resulting in high turnover rates and a job tenure averaging 3 years. ${ }^{11}{ }^{12}$ Due to the reality of burnout and CF among OTDCs, and the lack of publications examining these issues, we decided to explore this topic further.

\section{Objective}

This study aimed to collate and synthesise the available literature on burnout and CF among OTDCs by conducting a scoping review to respond to the research question: what is known about burnout and CF among OTDCs worldwide?

Our objectives were (1) to develop a comprehensive description of burnout and CF in OTDCs, (2) to map the risk and protective factors, consequences and strategies to deal with burnout and/or CF among OTDCs worldwide and (3) to summarise and disseminate key aspects of burnout and CF among OTDCs worldwide.

\section{METHODS}

This systematic scoping review was conducted following the Joanna Briggs Institute methodology for scoping reviews. ${ }^{13}{ }^{14}$ A scoping review design was used to formulate search strategy, synthesize evidence, map the existing literature related to a specific field and to identify key concepts and gaps in the literature. ${ }^{14}$ The complete scoping review protocol is published elsewhere. ${ }^{15}$

\section{Inclusion and exclusion criteria}

This scoping review considered studies that describe aspects of burnout or CF among OTDCs and explored defining characteristics, underlying factors, triggers, consequences, protective factors and management strategies. As scoping reviews are by nature exploratory, we also considered studies that investigated moral distress, attrition, grief, vicarious trauma, secondary trauma, conflict, anxiety, psychological distress, post-traumatic stress disorder, depression, and resilience. For the participants, we considered any HCP in the role of OTDC worldwide.

\section{Search strategy}

A three-step search strategy was used to find both published and unpublished materials. A health sciences librarian with expertise in systematic reviews was responsible for creating the search strategy. First, an initial limited search of Medline (Ovid) was undertaken and analysed for text words contained in the titles, abstracts and index terms used to describe articles. That initial search informed the development of a search strategy tailored for each information source. Next, a search strategy was developed based on these results, peer-reviewed using Peer Review of Electronic Search Strategies ${ }^{16}$ and then adapted for the syntax and subject heading of each database. Finally, the reference lists of all included reports and articles were searched for additional studies.

The search parameters were adapted and applied to the following databases: Medline, EMBASE, PsycINFO, CINAHL, LILACS and PTSpubs (online supplemental appendix A). Google Scholar was searched through Publish or Perish, and the first 100 records were retained. Additionally, grey literature was included through Research Gate, OpenGrey, open access theses and dissertations, ODO websites, as well it was requested from ODOs in North America, South America and Europe. Where possible, searches were limited to English, French, Portuguese or Spanish, the languages read by the review team and date limited to the years 1980-2020. A full search was performed in December 2019 and updated in April 2020 after testing the Medline search against the included studies. ${ }^{17}$ The testing resulted in one additional term being added to the searches for the Ovid databases.

\section{Study selection}

Records retrieved by the electronic search were downloaded and imported into a Reference Manager software to remove duplicates, and then uploaded to Covidence online data screening platform. ${ }^{18}$ Throughout the review, an iterative approach was used, and new records identified in the different steps of the screening/extraction phases were integrated for review. Records were reviewed 
against the inclusion criteria. Three reviewers (VSS, AR and ARS) independently assessed the titles and abstracts of the papers identified from the search. In the case of conflicts in the inclusion decisions, a fourth reviewer (JA) was consulted. The full-text articles selected for inclusion were screened and assessed by the same three reviewers (VSS, AR and ARS).

\section{Data extraction and synthesis}

Data was extracted by three independent reviewers using a data extraction tool that was developed by the researchers and pilot tested specifically for this scoping review. The data extraction included details about study design, sample, core concepts, context and key findings relevant to our objectives. Additionally, NVIVO was used to perform a qualitative directed content analysis to summarise and synthesise the results from the scoping review. ${ }^{19}$ The data analysis was an iterative process, in which we used a combination of inductive and deductive coding approaches. Structured coding was used based on the pre-existing concepts from the literature, ${ }^{420}$ and emergent coding was used for additional emerging themes. ${ }^{21}$ During the analysis process, the codes were recorded and tallied to find the majority consensus across the data.

\section{Patient and public involvement}

Family members who experienced the organ donation process, by donating the organs of their loved ones, were involved in this study to provide their perspectives in regard to the terms selected for the search strategy for this study, and they reviewed this manuscript before publication.

\section{RESULTS}

A total of 741 records were identified through the database search and other sources, resulting in 700 records for screening after duplicates were removed; 29 studies met the defined inclusion criteria and were included in this scoping review. Details related to search results and study selection in this review can be found in the Preferred Reporting Items for Systematic Reviews and Meta-analyses Extension for Scoping Reviews ${ }^{22}$ flow chart in figure 1. Of the 29 articles selected, the majority were published in the USA $(n=7,24 \%)$, Canada $(n=6,21 \%)$ and Brazil $(\mathrm{n}=6,21 \%)$, between 2013 and $2020(\mathrm{n}=13,45 \%)$ in transplant journals $(\mathrm{n}=11,38 \%)$ and used a qualitative design approach $(\mathrm{n}=12,41 \%)$ (table 1$)$. Researchers did not use consistent terms when referring to burnout and CF, but through qualitative thematic analysis approach, we were able to identify 13 themes that were grouped into five categories (table 2):

1. burnout characteristics: the set of situational attributes that are the prime correlates of burnout and its process of prolonged exposure to job stressors.

2. CF characteristics: factors that are specific to $\mathrm{CF}$ as the process of traumatisation of helpers through their effort of helping others.
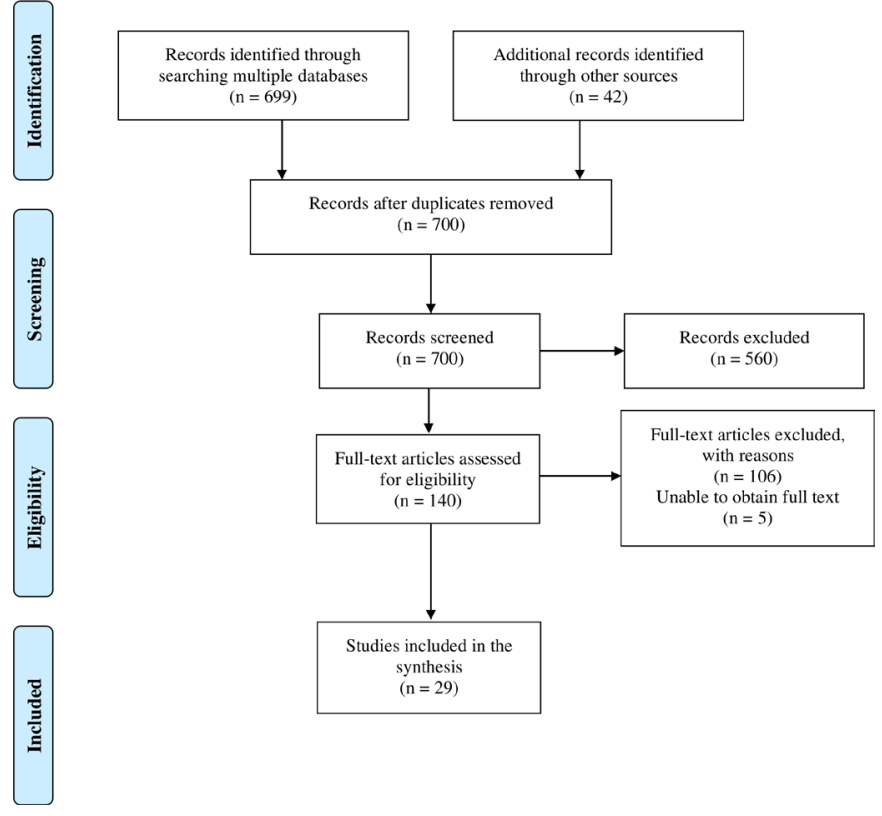

Figure 1 Scoping review results in a modified Preferred Reporting Items for Systematic Reviews and Meta-analyses Extension for Scoping Reviews diagram.

3. coping strategies: the use of behavioural and psychological effort to help to overcome, minimise or manage stressful situations and experiences.

4. ambivalence: the state of having contradictory emotions and ideas concerning something or someone.

5. protective factors: the aspects and attributes used by individuals or groups to reduce the risk of being negatively impacted by a problem or situation.

\section{THEMES AND DISCUSSION \\ Burnout characteristics \\ Demographic characteristics}

We identified age, marital status and sex as factors that increased risk of developing burnout among OTDCs in four papers. ${ }^{32-25}$ Burnout levels were identified as being greater among OTDC who were men, ${ }^{24}$ with higher educational levels, ${ }^{24}{ }^{25}$ full-time coordinators,${ }^{24}$ working fewer years as an OTDC $^{3}$ and being physicians who performed OTDC duties. ${ }^{25}$ Reports of the role of marital status $^{2425}$ and age ${ }^{32324}$ were contradictory across publications. Therefore, variables such as sex, educational level and type of employment should be considered when investigating burnout risk. ${ }^{26}$

\section{Exhaustion}

OTDCs described feelings of exhaustion as the depletion of emotional and physical resources. We detected this attribute in six papers. ${ }^{3}{ }^{2326-28}$ Dealing regularly with death and loss can evoke feelings of tiredness, sadness and fear among OTDCs. ${ }^{27}$ They also deal with unpredictable routine, overtime work, fast-paced environment, the constant sense of urgency and on-call shifts, which can lead to physical and emotional exhaustion through sleep deprivation, lack of concentration, intolerance and loss 
Table 1 Characteristic of included references

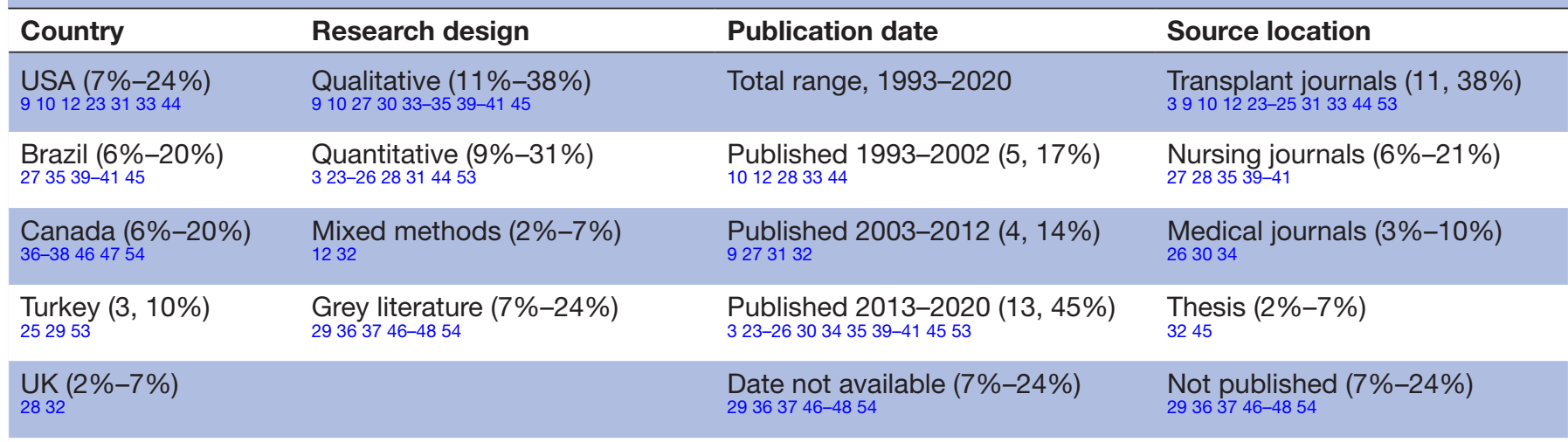

China (1\%-3\%)

24

Italy $(1 \%-3 \%)$

26

Spain (1\%-3\%)

34

Poland $(1 \%-3 \%)$

Israel (1\%-3\%)

of interest in the job. ${ }^{26-28}$ Emotional exhaustion, when measured as an underlying factor of burnout, refers to the feeling of depletion due to the accumulated stress in the workplace and it has a higher incidence among professionals who are in a relationship, ${ }^{3}$ working more hours per week, ${ }^{23}$ with lower supervisor support, ${ }^{23}$ more difficult patient interactions, ${ }^{23}$ greater psychological job demand ${ }^{23}$ and low psychological well-being. ${ }^{23}$ Although age was not a statistical predictor of exhaustion, the years

\begin{tabular}{llc}
\hline Table 2 & Distribution of articles per theme & \\
\hline Themes & Codes within themes & No. (\%) \\
\hline $\begin{array}{l}\text { Burnout } \\
\text { characteristics }\end{array}$ & $\begin{array}{l}\text { Demographic } \\
\text { characteristics }\end{array}$ & $4(13.8)$ \\
& $\begin{array}{l}\text { Exhaustion } \\
\text { Personal accomplishment }\end{array}$ & $6(20.7)$ \\
& Job attitudes & $2(6.9)$ \\
& Job characteristics & $3(10.3)$ \\
& Burnout consequences & $4(13.8)$ \\
\hline $\begin{array}{l}\text { Compassion fatigue } \\
\text { characteristics }\end{array}$ & $\begin{array}{l}\text { Compassion fatigue } \\
\text { precursors }\end{array}$ & $9(31)$ \\
& $\begin{array}{l}\text { Compassion fatigue } \\
\text { consequences }\end{array}$ & $6(20.7)$ \\
Coping strategies & $\begin{array}{l}\text { Depersonalisation as a } \\
\text { coping strategy }\end{array}$ & $3(10.3)$ \\
& Management Strategies & $15(51.7)$ \\
\hline Protective Factors & Job engagement & $10(34.5)$ \\
\hline Ambivalence & $\begin{array}{l}\text { Value conflict } \\
\text { Emotional contradiction }\end{array}$ & $2(31)$ \\
\hline
\end{tabular}

of working as an OTDC were a significant predictor, where professionals with fewer years of experience were more susceptible to emotional exhaustion. ${ }^{3}$ Burnout prevalence may be negatively associated with emotional intelligence but positively related to the incidence of $\mathrm{CF}$ among OTDCs. ${ }^{29}$ Thus, due to the high demand and the nature of OTDCs' job, these professionals are often affected by emotional exhaustion and/or at an increased risk of burnout and $\mathrm{CF}$ incidence.

\section{Personal accomplishment}

Reduced personal accomplishment represents the selfevaluation component of burnout, which can include reduction of one's productivity, competence and selfefficacy, and it is considered one of the core dimensions of burnout. ${ }^{20}$ We identified this attribute in three papers. ${ }^{232530}$ One study reported that OTDCs described more personal accomplishment ${ }^{23}$ than other nurses involved in the process of organ donation and transplantation, while another highlighted that OTDCs had a mid-level score on the personal accomplishment dimension of the Maslach Burnout Inventory. ${ }^{25}$ OTDCs who were women, ${ }^{23}$ younger age,${ }^{23}$ single,${ }^{25}$ non-physician, ${ }^{25}$ working with lower decisional authority ${ }^{23}$ and with high levels of discomfort when dealing with difficult patient interactions ${ }^{23}$ were more susceptible to having a reduced personal accomplishment. Also, OTDCs may face situations where they have responsibilities without authority resulting in a sense of powerlessness that negatively affect their feelings of personal accomplishment. ${ }^{30}$ Therefore, personal accomplishment is considered a component of burnout, but the studies that investigated this attribute 
did not report reduced levels of personal accomplishment among OTDCs according to the Maslach Burnout Inventory subscale scores. ${ }^{2325}$

\section{Job attitudes}

Job attitudes included OTDC behaviour and expectations related to their role and work. We identified this attribute in two articles. ${ }^{91}$ People can have different expectations attached to their job, but when the expectations about the success and nature of the job are too high or unrealistic, this can be a risk factor for developing burnout. ${ }^{4}$ Because people with higher expectations of their job tend to work harder than others, the lack of results from this effort can lead them to exhaustion and/or cynicism. ${ }^{4}$ The complexity of organ donation processes often demands a lot from OTDCs. As OTDCs are aware of their central role in the donation process, it is not uncommon for them to dedicate extra time and effort to a case. ${ }^{10}$ The extra work put into cases can lead OTDCs to develop high levels of self-criticism, resulting in a constant feeling that they have not done enough during the process. ${ }^{9}$ On the other hand, the fulfilment from work performance and clear perception of the OTDC role might help them to develop a higher sense of satisfaction. ${ }^{31}$ Although it is important to these professionals to be committed to their job, they also need to develop a balance between self-criticism and work satisfaction, as an imbalance may result in OTDCs resigning from their job. ${ }^{931}$

\section{Job characteristics}

There were a number of quantitative and qualitative job characteristics identified in the literature including worked hours, number of patients, the severity of clients' problems, role conflict and role ambiguity. We identified various job characteristics in three papers. ${ }^{102332}$ The OTDC role is frequently described as stressful and exhausting, with factors such as cases that surpass 30 hours, with sleep deprivation and little or no time to eat, resulting in fatigue during this period. ${ }^{10}$ The OTDC role also involves frequent exposure to difficult and uncomfortable interactions with the patient's family. ${ }^{23} 32$ Although the complexity of the OTDC role is unquestionable, there is a lack of resources and protocols to support their activities, particularly related to social and psychological support to help them overcome difficult cases. ${ }^{32}$ Therefore, the use of education and psychological support are highlighted in the literature as possible resources to sustain their psychological health and help them to build boundaries between work and personal life.

\section{Burnout consequences}

For this attribute, we included reports of the consequences associated with burnout presented in the personal and professional lives of OTDCs. We identified this attribute in four articles. ${ }^{10} 122831$ At the professional level, the most common consequences identified in the literature were high levels of stress and emotional burden, combined with an inadequate support system for coping with stressors, leading to resignation ${ }^{10}$ and use of medical leave. ${ }^{28}$ Turnover levels were reported as being higher among those who are younger OTDCs, ${ }^{12}$ spend more days on call, ${ }^{2831}$ work long hours, receive poor remuneration, are exposed to poor management and are overstressed or emotionally exhausted. ${ }^{31}$ Boundaries between professional and personal life are blurred for most OTDCs. The uncertainty of being called to work even during off call hours was reported as negatively affecting OTDCs' offcall time as it prevents them from disconnecting from their job. ${ }^{28}$ Therefore, although burnout is a syndrome that originates from work stressors, the consequences also impact OTDCs' personal life.

\section{Compassion fatigue characteristics \\ Compassion fatigue precursors}

The precursors to the development of CF identified in the literature include the constant exposure to suffering or traumatised people. We identified this characteristic in nine reports. ${ }^{9} 10122732-36$ In addition to working in a high-pressure and demanding environment, OTDCs are exposed to the suffering of families. ${ }^{9} 10122732-34$ OTDCs are responsible for approaching families to inform them of the possibility of organ donation after families have learnt about the death (potential donors from neurological determination of death) or imminent death (potential donors from circulatory determination of death) of their loved one. The unpredictability of the reactions of the family to the approach ${ }^{27} 32333536$ generates hightension and stressful scenarios. ${ }^{27} 32$ The high level of dedication to organ donation processes may lead OTDCs to feel vulnerable and exhausted. ${ }^{9}$ Thus, OTDCs can find themselves crying, in a depressive mood and emotionally unstable,${ }^{9}$ especially after difficult cases such as the ones involving childre ${ }^{32} 33$ or if the case brings up personal experiences and memories. ${ }^{36}$ These are some of the reasons why OTDCs refer to the family approach as the most stressful part of their job. As family approaches are an inevitable part of the OTDCs role and are highly emotionally charged, ${ }^{27} 3234$ it may be identified as a possible precursor to the development of CF.

\section{Compassion fatigue consequences}

We identified six papers mentioning the development of a variety of psychological and physical signs and symptoms consequent to CF. ${ }^{98}{ }^{35-38}$ The most common symptoms of CF in OTDCs reported in the literature were suffering, despair, anguish, anger, irritability, ${ }^{35}$ intrusive thoughts about donors and their families ${ }^{9}$ and difficulty sleeping. ${ }^{9}{ }^{28}$ Canadian ODOs that collaborated on this study shared some materials used either to advertise resources to their OTDCs or to train them in recognising and preventing burnout and vicarious trauma. One of the materials pertained to an external course provided to OTDCs and contained a description of physical behaviours and psychological symptoms of CF. ${ }^{36}$ The other material shared was the outline of a workshop delivered to OTDCs in which the trajectory of CF was highlighted: 'the zealot 
phase (excitement, commitment, extra hours); the irritability phase (strained humour, avoidant, irritable); the withdrawal phase (defended, exhausted, neglectful); the zombie phase (automatic pilot, no meaning in work, loss of compassion); pathology and victimisation versus renewal and maturation phase (leaving work vs transformation and resilience) ${ }^{3} .{ }^{37} \mathrm{CF}$ symptoms and signs can be challenging to identify; therefore, it is important that OTDCs are aware of what to look for among themselves and co-workers.

\section{Coping strategies}

Depersonalisation as a coping strategy

We included three reports describing individual detachment from patients' families to avoid engagement and/or empathy as a way to deal with pain and suffering. ${ }^{202739-41}$ Although depersonalisation is considered one of the three dimensions of burnout, it is also linked to $\mathrm{CF}^{42}{ }^{43}$ Some OTDCs see depersonalisation as something natural, as an attempt to protect themselves from the exposure to families' feelings. ${ }^{27} 3940$ However, depersonalisation was also identified as a strategy in relation to the patients. For example, some OTDCs provide care for brain dead donors as if they were still alive, putting a barrier in between themselves and the donor in order to be able to provide assistance while not absorbing feelings that might cause sadness and suffering. ${ }^{27}$ This attitude of withdrawing one's feelings to look after patients is a protective strategy and a response to emotional exhaustion, and it can happen in such a natural manner that OTDCs may not be aware of their own detachment. ${ }^{27}$ Therefore, depersonalisation can occur as a result of burnout or CF, and it impacts OTDCs' clinical practice as well as patient and family care, yet it can be difficult to recognise and diagnose.

\section{Management strategies}

There were a number of management strategies, including the use of support groups as ways of managing burnout or CF, that were identified in 15 reports. ${ }^{9} 10262732333637404144-49$ OTDCs frequently seek an equilibrium between positive and negative emotions. Even though the OTDC's role involves dealing with death and grief, it is also seen as a valuable service that supports family members ${ }^{927}$ and helps save numerous recipients' lives. ${ }^{927}$ Another important management strategy for OTDCs is the role of colleagues as a continuous source of support. ${ }^{9} 323345$ OTDCs rely heavily on colleagues when seeking support or advice, as the similarity of experiences brings higher levels of comfort and trust in comparison with management, families or other HCPs. ${ }^{9} 1045$ Other common strategies include, but are not limited to, the use of professional support (eg, therapist), ${ }^{3346}$ spirituality, ${ }^{40} 45$ religion, ${ }^{4145}$ muscle relaxation exercise, ${ }^{36}$ self-regulation activities, ${ }^{36}{ }^{47}$ reflective journal writing, ${ }^{47}$ improvement of quality of work life, ${ }^{44}$ team work, ${ }^{26} 3345$ meditation and attitude of gratitude development. ${ }^{36} 374148$ Management strategies were highlighted in the literature as techniques to help OTDCs cope with and control consequences of burnout and CF, therefore supporting their well-being.

\section{Ambivalence}

\section{Value conflict}

Value conflict describes the consequence of incompatible belief systems that can result in suffering and moral distress. ${ }^{40}$ We identified value conflict in nine papers. ${ }^{9} 1027303234364145$ OTDCs have a constant focus on increasing donation rates; however, while trying to receive approval from donor families, they can face situations in which their attitudes might not be in accordance with their values. ${ }^{1030343645}$ For instance, OTDCs are often requested to approach families when they believe it is not appropriate, but due to protocols and organisational pressure, they proceed with the approach against their beliefs. ${ }^{10} 3445$ In some countries, OTDCs may face situations that violate ethical principles. One example is when families agree to donate the organs of their loved one since it is directed to a specific person, or only if the recipient is of a particular religion. By fulfilling those requests, OTDCs may experience emotional pain and guilt. ${ }^{30}$

Additionally, sometimes OTDCs know that the donor is not ideal for donation, but they are still told to go forward with the procedure by management, offering less than optimal organs for transplantation, slowing down the process for staff and the donor's family. ${ }^{930}$ In unfortunate cases, patients declared brain dead receive less optimal and even precarious treatment by the care team since they do not see the point in continuing treatments, causing ethical and emotional conflicts among OTDCs and the care team. ${ }^{41}$ Some OTDCs do not declare themselves as donors even though they work towards increasing organ donation rates, claiming that they know how the system and procedures work. ${ }^{27} 32$ In an unremitting attempt to obtain organ donations, OTDCs sometimes end up facing frustration, disappointment and a feeling of helplessness during the organ donation process, resulting in value conflicts and moral distress. ${ }^{45}$ The constant exposure to conflicts between job demands and core values can make OTDCs susceptible to burnout. ${ }^{50}$

\section{Emotional contradiction}

Emotional contradiction is described as a conflict between enjoying and disliking the work and its tasks, which was identified in two papers. ${ }^{28}{ }^{34}$ As mentioned previously, OTDCs have a high level of job satisfaction as their job provides a sense of achievement and fulfilment. ${ }^{9} 3132$ However, there is a conflict where satisfaction and compromise may not be enough to counteract the difficulties and requirements involved in the OTDCs' role. ${ }^{34}$ The amount of on-call work required from OTDCs can also impact this ambivalence. ${ }^{28}$ Therefore, due to their demanding clinical practice, OTDCs may face challenges while trying to balance positive and negative feelings toward work requirements and roles. 


\section{Protective factors}

Job engagement

Job engagement was described as the extent of a workrelated state of mind where HCPs feel enthusiastic and energetic about their job, and it can include aspects such as satisfaction, vigour, fulfilling, motivation and dedication. ${ }^{51}{ }^{52}$ We identified various aspects of job engagement in 10 papers. ${ }^{9} 122326313235444553$ OTDCs can be negatively affected by stressors in the workplace, but their job also brings positive aspects that help them to overcome obstacles and to build work resilience.$^{45}$ Resilience can be defined as the ability to recover from difficult situations, and this process can involve the use of coping strategies and protective factors. ${ }^{4}$ OTDCs describe themselves as having great levels of resilience, as even though they suffer the emotional impact from work situations, they still have the ability to recover and keep working. ${ }^{45} 53$ Job satisfaction has a positive influence on resilience, and even with stressors and workloads, OTDCs are considered to have a high level of job satisfaction because their job provides a sense of achievement, gratitude, excitement, recognition and fulfilment. ${ }^{9} 2232631323544$ Job characteristics such as work hours, on-call schedule, workload, stress and compensation can directly impact the job satisfaction level among OTDCs. ${ }^{31}{ }^{53}$ Also, the quality of work-life was found to have a positive impact on employee morale, satisfaction and retention. ${ }^{44}$ Therefore, job engagement can impact OTDC resilience and job satisfaction and, if this influence is positive, it can result in increased retention rates.

\section{STRENGTHS AND LIMITATIONS}

There are some limitations to this scoping review that are worth noting. Although our results may have omitted evidence in languages other than English, Portuguese, French and Spanish, we included the languages of the regions where the OTDC's role is most developed and established. Second, the focus of scoping reviews is to provide breadth rather than depth of evidence on a particular area; therefore, scoping reviews are inherently limited. However, given that our objective was to map the evidence related to burnout and CF for OTDCs, this method was appropriate. The results of this scoping review have identified knowledge gaps suggesting a need for further high-quality primary research with OTDCs. The use of inconsistent language for the concepts of burnout and $\mathrm{CF}$ in the literature may have contributed to us missing relevant articles, and in the future, it would be valuable for researchers and clinicians to use more consistent terminology in order to gain a better understanding of the extent of the issues.

\section{CONCLUSION}

This scoping review identified aspects of burnout and CF among OTDCs, including defining characteristics, demographic predispositions, protective factors, coping strategies, precursors, consequences and personal ambivalences. Although characteristics of burnout and CF were identified in multiple documents, many authors did not clearly mention burnout and CF or used inconsistent terms when referring to $\mathrm{CF}$ and burnout. Overlap was found between symptoms related to $\mathrm{CF}$ and those related to burnout. The prevalence of burnout has been found to be positively related to incidence of $\mathrm{CF}$ among OTDCs. We therefore suggest that future research should explore the interaction and potential mutual influence between $\mathrm{CF}$ and burnout rather than only focusing on these phenomena separately. There is a clear need to further investigate the issues of burnout and CF in this population by using a systematic approach and appropriate research methods that combine quantitative and qualitative investigation to examine the underlying reasons for the development of burnout and CF among OTDCs, so that methods can be developed to assist HCPs working in this role.

Acknowledgements The authors would like to acknowledge Queen's Collaboration for Healthcare Quality at JBI Centres of Excellence team that guided the development of the research protocol. The authors thank the patient partners Peter Wright and Diana Brodrecht for reviewing the manuscript. The authors also thank Dr Elaine Cheung and Dr Peter Dodek for their contributions to the development of this work. We thank Canadian Blood Services and the Canadian Donation and Transplantation Research Program for supporting this work. We thank Katie O'Hearn, MSc, (Children's Hospital of Eastern Ontario Research Institute) for methodological assistance, Amanda Ross-White, MLIS, AHIP (Bracken Health Sciences Library, Queen's University) for developing the phase 1 search and peer review of the main Medline search strategy and Margaret Sampson, MLIS, PhD, AHIP (Children's Hospital of Eastern Ontario) for developing the main electronic search strategies and updating the searches. We thank David Kuhl for reviewing the search terms list and suggesting additional key terms for the search strategy building. The authors thank the Canadian Organ Donation Organisations and the Crisis and Trauma Resource Institute for providing grey literature material.

Contributors VSeS, LH, KL, AA and SD contributed to the conception and design of the study. JA contributed to the design of the study. VSeS, ARS and AR screened articles and performed data extraction. VSeS, ARS and JA interpreted the data. VSeS and ARS drafted and all authors critically reviewed the manuscript. All authors read and approved the manuscript.

Funding This work was supported by Canadian Blood Services. Funding grant number not applicable.

Competing interests $\mathrm{LH}$ is a paid part-time consultant for Canadian Blood Services. AR is a research assistant and receives a salary from Canadian Blood Services. ARS is a research assistant and receives salary from Canadian Blood Service. VSeS is a paid full-time research coordinator and receives salary from Canadian Blood Service. KL is a paid employee of Canadian Blood Services and the programme is a charitable organisation funded by federal and provincial governments.

Patient consent for publication Not required.

Provenance and peer review Not commissioned; externally peer reviewed.

Data availability statement Data sharing not applicable as no datasets generated and/or analysed for this study. No additional data are available.

Supplemental material This content has been supplied by the author(s). It has not been vetted by BMJ Publishing Group Limited (BMJ) and may not have been peer-reviewed. Any opinions or recommendations discussed are solely those of the author(s) and are not endorsed by BMJ. BMJ disclaims all liability and responsibility arising from any reliance placed on the content. Where the content includes any translated material, BMJ does not warrant the accuracy and reliability of the translations (including but not limited to local regulations, clinical guidelines, terminology, drug names and drug dosages), and is not responsible for any error and/or omissions arising from translation and adaptation or otherwise. 
Open access This is an open access article distributed in accordance with the Creative Commons Attribution Non Commercial (CC BY-NC 4.0) license, which permits others to distribute, remix, adapt, build upon this work non-commercially, and license their derivative works on different terms, provided the original work is properly cited, appropriate credit is given, any changes made indicated, and the use is non-commercial. See: http://creativecommons.org/licenses/by-nc/4.0/.

ORCID iD

Vanessa Silva e Silva http://orcid.org/0000-0002-0717-2011

\section{REFERENCES}

1 Koinis A, Giannou V, Drantaki V, et al. The impact of healthcare workers job environment on their Mental-emotional health. Coping strategies: the case of a local General Hospital. Health Psychol Res 2015;3:1984.

2 Sinclair S, Raffin-Bouchal S, Venturato L, et al. Compassion fatigue: a meta-narrative review of the healthcare literature. Int J Nurs Stud 2017;69:9-24.

3 Bury M, Rozenek H, Kamiński A, et al. Professional burnout and its correlates in Polish donor transplant coordinators. Cell Tissue Bank 2019;20:535-44.

4 Maslach C, Schaufeli WB, Leiter MP. Job burnout. Annu Rev Psychol 2001;52:397-422.

5 Monsalve-Reyes CS, San Luis-Costas C, Gómez-Urquiza JL, et al. Burnout syndrome and its prevalence in primary care nursing: a systematic review and meta-analysis. BMC Fam Pract 2018;19:59.

6 Salmond E, Salmond S, Ames M, et al. Experiences of compassion fatigue in direct care nurses: a qualitative systematic review. JBI Database System Rev Implement Rep 2019;17:682-753.

7 van Mol MMC, Kompanje EJO, Benoit DD, et al. The prevalence of compassion fatigue and burnout among healthcare professionals in intensive care units: a systematic review. PLoS One 2015;10:e0136955.

8 Matesanz R, Domínguez-Gil B, Coll E, et al. Spanish experience as a leading country: what kind of measures were taken? Transp/ Int 2011;24:333-43.

9 Blumenthal PA. "It's not a job; it's a lifestyle": the experience of being a donation coordinator. Prog Transplant 2007;17:8-22.

10 Gimbel RW, Strosberg MA, Lehrman SE. Cultural analysis of an organ procurement organization. Prog Transplant 2001;11:249-54.

11 Bush NJ. Compassion fatigue: are you at risk? Oncol Nurs Forum 2009;36:24-8.

12 Taylor G, McGaw J, Mayes G, et al. The coordinator attrition problem in the United States: myth or reality? J Transp/ Coord 1998;8:88-92.

13 Peters MDJ, Godfrey CM, Khalil H, et al. Guidance for conducting systematic scoping reviews. Int J Evid Based Healthc 2015;13:141-6.

14 Peters MDJ, Godfrey C, Mclnerney P. Scoping Reviews. In: Joanna Briggs Institute Reviewer's Manual [Internet]. Adelaide: Joanna Briggs Institute, 2017.

15 Silva E Silva V, Hornby L, Almost J, et al. Burnout and compassion fatigue among organ donation coordinators: a scoping review protocol. JBI Evid Synth 2020;18:2435-42.

16 McGowan J, Sampson M, Salzwedel DM, et al. PRESS Peer Review of Electronic Search Strategies: 2015 guideline statement. J Clin Epidemiol 2016;75:40-6.

17 Sampson M, McGowan J. Inquisitio Validus Index Medicus: a simple method of validating Medline systematic review searches. Res Synth Methods 2011;2:103-9.

18 Covidence. Covidence systematic review software. Melbourne, Australia: Veritas Health Innovation. Available: https://www. covidence.org/ [Accessed Apr 2020].

19 Hsieh H-F, Shannon SE. Three approaches to qualitative content analysis. Qual Health Res 2005;15:1277-88.

20 Bresó E, Salanova M, Schaufeli WB. In search of the "third dimension" of burnout: efficacy or inefficacy? Appl Psychol 2007;56:460-78.

21 Gibbs G. Analyzing qualitative data. SAGE, 2007

22 Tricco AC, Lillie E, Zarin W, et al. PRISMA extension for scoping reviews (PRISMA-ScR): checklist and explanation. Ann Intern Med 2018;169:467-73.

23 Jesse MT, Abouljoud MS, Hogan K, et al. Burnout in transplant nurses. Prog Transplant 2015;25:196-202.
24 Mao P, Cai P, Luo A, et al. Factors in organ donation coordinators: a cross-sectional study in China. Ann Transplant 2018;23:647-53.

25 Harmanci Ak CA, Kemalogly B, Kahveci E B. Burnout syndrome in organ transplantation coordinators in Turkey. Cells Tissues Organs 2013;16:59-69.

26 Ponzin D, Fasolo A, Vidale E, et al. Team-building through sailing: effects on health status, job satisfaction and work performance of health care professionals involved in organ and tissue donation. $G$ Ital Med Lav Ergon 2015;37:184-90.

27 Lima A, Silva M, Pereira L. Sofrimento e contradição: o significado da morte e do morrer para enfermeiros que trabalham no processo de doação de órgãos para transplante. Enfermeria Global 2009;15:1-17.

28 Smithers F. The pattern and effect of on call work in transplant coordinators in the United Kingdom. Int J Nurs Stud 1995;32:469-83.

29 Harmanci AK. Evaluating the relationship between burnout levels and compassion fatigue, emotional intelligence, communication skills of organ transplant coordinators, 2020.

30 Tarabeih M, Bokek-Cohen Ya'arit, Bokek-Cohen Y. Between health and death: the intense emotional pain experienced by transplant nurses. Nurs Inq 2020;27:e12335.

31 Kress J, Smith DL, Fehling PC, et al. Improving the recruitment and retention of organ procurement coordinators: a survey study. $A m \mathrm{~J}$ Transplant 2009;9:1451-9.

32 Neades BL. Healthcare professionals' experiences in applying presumed consent legislation in organ donation in three European countries: a phenomenological study 2007:1-432.

33 Kennedy CW, Jones LL. Procurement coordinator support group. J Transpl Coord 1997;7:32-5.

34 Danet Danet A, Jimenez Cardoso PM, Pérez Villares JM. Emotional paths of professional experiences in transplant coordinators. Nefrologia 2020;40:75-90.

35 PIMNd F, de Melo Tavares CM. Emotions experienced by transplant coordinators in family interviews for organ donation. Ciencia cuidado e saude 2016;15:53-60.

36 Crisis \& Trauma Resource Institute. Vicarious Trauma - Strategies for Resilience, 2020.

37 Spilman J. Caring on empty workshop.

38 Mathieu F. The compassion fatigue workbook, 2012.

39 PIMNd F, de Melo Tavares CM. Emotional preparedness of health professionals in family interviews: a hermeneutic study. Online Braz J Nurs 2014;13:496-506.

40 PIMNd F, CMdM T. O manejo das emoções dos coordenadores em transplantes na realização da entrevista familiar para doação de órgãos. Revista portuguesa de enfermagem de saúde mental 2015;2:39-44.

41 PIMNd F, Tavares CS, Nascimento Vdo. Situacoes dificeis e seu manejo na entrevista para doacao de orgaos. Revista portuguesa de enfermagem de saúde mental 2016:69-76.

42 Kase SM, Weintraub A, Gribben J, et al. A cross-sectional analysis of compassion fatigue, burnout, and compassion satisfaction in pediatric critical care providers in the US. Pediatr Crit Care Med 2019;144(2 MeetingAbstract):358-58

43 Powell SK. Compassion fatigue. Prof Case Manag 2020;25:53-5.

44 Haid SD, House KA, Kea SM, et al. Effect of quality of work life plan on employee recruitment and retention at organ recovery systems, Inc. J Transp/ Coord 1993;3:18-22.

45 Fonseca P. O autoconhecimento e sua multidimensionalidade aplicada equipes de transplantes, 2017

46 Mazanec SR, Sandstrom K, Coletta D, et al. Building family caregiver skills using a simulation-based intervention: a randomized pilot trial. Oncol Nurs Forum 2019:46:419-27.

47 Specific resilience and healing strategies.

48 Cass J. When caring hurts: compassion fatigue and vicarious trauma.

49 PIMNd F. O autoconhecimento e sua multidimensionalidade aplicada equipes de transplantes, 2017.

50 Maslach C, Leiter MP. Burnout. Stress and quality of working life: current perspectives in occupational health. , 2006: 37, 42-9.

51 Vinje HF, Mittelmark MB. Job engagement's paradoxical role in nurse burnout. Nurs Health Sci 2007;9:107-11

52 Maslach C, Leiter MP. Early predictors of job burnout and engagement. J Appl Psychol 2008;93:498-512.

53 Soylu D, Soylu A, Korkmaz M, et al. Level of job satisfaction among organ transplant coordinators and difficulties experienced by them Transplant Proc 2019;51:2198-201.

54 PROQOL survey results. 